\title{
LAS IDEOLOGÍAS LINGÜÍSTICAS SOBRE LAS LENGUAS INDÍGENAS AMERICANAS: UNA REVISIÓN SISTEMÁTICA DE ARTÍCULOS DE INVESTIGACIÓN
}

\author{
Linguistic Ideologies About American Indigenous Languages: \\ A Systematic Review of Research Articles \\ LES IDÉOLOGIES LINGUISTIQUES SUR LES LANGUES INDIGÈNES AMÉRICAINES: \\ UNE RÉVISION SYSTÉMATIQUE D'ARTICLES DE RECHERCHE
}

\section{César Cisternas Irarrázabal \\ Maestrando en Ciencias Sociales \\ Aplicadas, Universidad de La Frontera, \\ Chile. \\ Docente del Departamento de Ciencias Sociales, Universidad de La Frontera, \\ Chile. \\ c.cisternas.irarrazabal@gmail.com https://orcid.}

org/0000-0002-4510-4239

\section{Aldo Olate Vinet}

Ph. D. en Lingüística, Universidad de

Concepción, Chile.

Docente del Departamento de Lenguas, Literatura y Comunicación, Universidad de La Frontera, Chile. aldo.olate@ufrontera.cl

https://orcid.

org/0000-0002-6926-769X

\begin{abstract}
RESUMEN
La comprensión de las ideologías lingüísticas es fundamental para la descripción de los procesos de conservación y desplazamiento de las lenguas minorizadas. Este trabajo revisa, de manera sistemática, las publicaciones indexadas en Web of Science que abordan el tópico de las ideologías lingüísticas sobre lenguas indígenas americanas, con el propósito de describir las líneas de investigación, las orientaciones metodológicas, los enfoques teóricos, las tipologías y las conclusiones más relevantes que presentan para el campo. La revisión abarca un rango temporal que se extiende desde 1980 hasta 2016, y produjo 25 artículos. Los resultados muestran que, en las publicaciones, hay una orientación metodológica exclusivamente cualitativa, mientras que, en lo conceptual, se observa una extensa taxonomía de ideologías, que incluye diversas denominaciones para un mismo marco ideológico. También se evidencia la relevancia de las ideologías lingüísticas en procesos como la construcción de la identidad, la revitalización lingüística, la planificación, la valoración de las lenguas, la resistencia identitaria-cultural, entre otros procesos sociolingüísticos y socioculturales.
\end{abstract}

Palabras clave: ideologías lingüísticas; lenguas minorizadas; lenguas indígenas americanas; lenguas indígenas.

\section{Abstract}

The comprehension of language ideologies is essential for describing the processes of conservation and displacement of minority languages. This work carries out a systematic review of the publications on language ideologies about American

Recibido: 2019-10-01 / Aceptado: 2019-10-10 / Publicado: 2020-09-17

https://doi.org/10.17533/udea.ikala.v25n03a09 
indigenous languages that are indexed in Web of Science. It has as its main purpose to describe the research lines, methodological orientations, theoretical frameworks, typologies, and the most relevant conclusions that those investigations provide to this field. The review considered articles published between 1980 and 2016, and produced 25 articles. Results show the prevalence of a methodological frame that is exclusively qualitative, while in the conceptual plane, a vast taxonomy of ideologies, which includes several denominations for the same ideological frame, is observed. They also reveal the relevance of language ideologies in processes such as identity construction, language revitalization, language planning, language valuation, cultural and identitary resistance, among other sociolinguistic and sociocultural processes.

Keywords: language ideologies; minoritized languages; American indigenous languages; indigenous languages.

\section{RÉSUMÉ}

La compréhension des idéologies linguistiques est fondamental pour décrire des processus de conservation et conversion des langues minoritaires. Cet article-ci fait une revue systématique des publications indexées sur Web of Science qui traitent le sujet des langues indigènes américains. Ça a le but de décrire les lignes thématiques d'investissement, les orientations méthodologiques, les cadres théoriques, les typologies textuelles et les conclusions plus remarquables dans ce domaine. La révision systématique a considéré une période de 1980 jusquà 2016, et a récupéré 25 articles. Les résultats montrent une orientation méthodologique exclusivement qualitatif, tandis qu'au niveau conceptuel nous avons observé une nombreuse taxinomie des idéologies qui donne des différentes dénominations au même cadre idéologique. Les études précédentes montrent l'importance des idéologies linguistiques en processus, comme la construction de l'identité, la revitalisation linguistique, la planification, la valorisation des langues, la résistance identitaire culturelle, parmi d'autres processus sociolinguistiques et socioculturels.

Mots clés : idéologie linguistique ; langues minoritaires ; langues indigènes américaines; langues indigènes. 


\section{Introducción}

América, con más de un centenar de familias lingüísticas, es el continente con la mayor diversidad lingüística a nivel mundial (Brown, 2006; Unicef, 2009). Su riqueza lingüística fue invisibilizada a lo largo del régimen colonial y durante el período de nacimiento y consolidación de los Estados nacionales, situación que cambia con la emergencia indígena de fines de la década de los setenta e inicios de la de los ochenta, tiempo en el que los movimientos indoamericanos empujan a los Estados a reconocer la existencia de las lenguas originarias y a establecer medidas tendientes a protegerlas.

Pero la resonancia de las demandas indígenas no se limitaría al plano político. La revalorización de sus lenguas se tradujo en un creciente interés por estudiarlas, labor que tuvo un escaso desarrollo en el siglo XIX y la primera parte del XX, siendo llevada a cabo principalmente por misioneros e intelectuales que conducían esfuerzos aislados por documentar y describir estas lenguas.

Desde sus inicios, la lingüística adoptó un acercamiento puramente descriptivo al estudio de las lenguas, considerando las creencias de los hablantes como un factor sin importancia o distorsionador en el análisis. Una visión de mayor complejidad, que incluye a los sujetos y los contextos en que se desenvuelven, se configura a partir de la década de los sesenta desde la etnografía de la comunicación (Kroskrity, 2004). Sin embargo, hacia fines de los años setenta, el trabajo de Silverstein (1979), al sugerir que el pensamiento de los hablantes sobre sus propias lenguas impacta en la manera en que estos la emplean, produce un giro radical en el paradigma dominante, sentando las bases del estudio de las ideologías lingüísticas. Desde entonces, gran cantidad de trabajos de investigación empírica y reflexión teórica sobre el tema se ha desarrollado en los campos de la antropología lingüística, la sociolingüística, la sociología del lenguaje, entre otros.

La estructuración epistemológica reciente del área implica que este ámbito de producción de conocimiento está en proceso de emergencia. Por ello, este trabajo se propone hacer una revisión de las investigaciones sobre ideologías lingüísticas de las lenguas indígenas americanas (LIA). Con el propósito de describir las líneas de investigación, los enfoques, las orientaciones metodológicas, las taxonomías proyectadas y las conclusiones más relevantes en este campo de estudio, se excluyen otras nociones, como representaciones sociales, percepciones o actitudes lingüisticas, para centrarse exclusivamente en el concepto de ideologías lingüisticas (IL) y destacar la manera en que se ha empleado este en la investigación de los sistemas de creencias sobre las LIA.

Una revisión sistemática permite establecer la forma en la que la perspectiva de las IL ha sido difundida en el estudio de las lenguas originarias de América, así como los métodos empleados y los ámbitos en que las IL se tornan relevantes para las dinámicas sociolingüísticas de estas lenguas.

Se ha optado por centrar la revisión sistemática en artículos indexados en Web of Science (WoS), publicados entre 1980 y 2016. La selección de esta base de artículos responde a que en ella figuran revistas de lingüística y de otras disciplinas asociadas al estudio de las lenguas de todo el mundo, y que cuentan con prestigio a nivel internacional.

Ciertamente, este ejercicio no entrega una imagen por completo acabada de la investigación sobre LIA, en cuanto la mayoría de los trabajos sobre lenguas indígenas habladas en países latinoamericanos -que conforman una buena parte del total de LIA - se publican en revistas en español indexadas en otras bases, como ERIH, Latindex, Redalyc, Scielo y Scopus.

Bajo ninguna circunstancia se quiere invisibilizar el amplio margen de contribuciones sobre este tópico en las otras bases de datos. Sin duda, explorar este tema en las bases de datos más usadas de Latinoamérica es una tarea que debe realizarse, pues esto permitirá ver la conformación del área desde nuestro territorio epistemológico. Sin embargo, en el ejercicio aquí presentado, tomamos 
en cuenta el criterio de "impacto (difusión) internacional”, aunque somos conscientes de que este está impulsado por el modelo de producción de conocimiento que se orienta hacia el cumplimiento de metas e indicadores.

Esta revisión, acotada al subgrupo de revistas con mayor potencial de impacto internacional, permite, además de describir las principales características de las publicaciones, dar cuenta de la presencia que tiene el estudio de las LIA dentro del campo de las IL a nivel mundial, lo cual se torna particularmente relevante, dada la situación de vulnerabilidad de estas lenguas. Por otra parte, la delimitación del lapso temporal, 1980-2016, se debe a que los estudios sobre IL comienzan a desarrollarse a partir de la década de los ochenta.

En el siguiente apartado se hace una revisión teórica del concepto de IL para, después, detallar la metodología empleada. Posteriormente, se presentan las principales tendencias de la investigación en el campo de las IL sobre LIA, finalizando con las conclusiones de este estudio.

\section{Ideologías lingüísticas}

Las creencias que los hablantes mantienen respecto de las lenguas han recibido creciente atención desde finales del siglo pasado. Entre los conceptos empleados para aproximarse a su estudio, la noción de IL — surgida en Estados Unidos, al alero de la antropología lingüística - ha suscitado interés desde la década de los ochenta, constituyendo una fecunda área de estudio. Su auge se debe, entre otros factores, a su utilidad como herramienta para revelar las visiones políticas sobre las cuales los hablantes elaboran representaciones de las lenguas (Garrett, 2010).

La evolución del concepto de IL ha sido abordada detalladamente por los autores en trabajos anteriores, como Cisternas (2017) y Olate et al. (2017). Con base en estos, a continuación se revisa el desarrollo que ha tenido este marco conceptual relativo a las creencias de los hablantes acerca de las lenguas.
La primera delimitación del concepto es entregada por Silverstein (1979), para quien las IL comprenden un conjunto de creencias que los hablantes tienen sobre la lengua, empleado para racionalizar ciertas estructuras y usos percibidos. Desde entonces, numerosos autores han planteado su propia perspectiva sobre esta noción. Irvine, por ejemplo, las describe como "un sistema cultural (o subcultural) de ideas sobre las relaciones sociales y lingüísticas, junto con sus cargas de intereses políticos y morales" (1989, p. 255), con lo que se explicita el trasfondo moral y político en que se configuran las IL. En un acercamiento coincidente, Woolard (1998) sostiene que las IL emergen a partir de relaciones complejas entre la posición social del hablante, sus prácticas lingüísticas y otras variables sociales, lo que activa representaciones sobre la interacción entre la lengua y el mundo social, perspectiva desde la cual las IL pueden ser manifestadas explícita o implícitamente en el discurso de los hablantes. Otra propuesta, que enfatiza la valoración sobre las variedades lingüísticas, es la de Spolsky (2004), para quien las IL son un conjunto de creencias que tiene una comunidad de habla sobre las prácticas lingüísticas apropiadas.

Una de las definiciones más populares de este campo de estudio la plantea Kroskrity (2004), cuya propuesta sostiene que una IL es un conjunto de creencias y sentimientos, implícitos y explícitos, sobre el uso de la lengua en el mundo social. Las creencias y los sentimientos los usan todos los hablantes para construir evaluaciones lingüísticas e involucrarse en la actividad comunicativa. El acento de esta visión está en que las IL, además de poder manifestarse de modo explícito o implícito, presentan un componente afectivo en su génesis.

El escenario teórico-conceptual en el que coexisten una serie de visiones diferenciadas por ciertos matices se condice con la constitución relativamente reciente del campo de estudio. Adicionalmente, las delimitaciones conceptuales más difundidas cuentan con un alto grado de abstracción, que deja abierto un amplio margen para su operacionalización y, por ende, para la interpretación del investigador 
respecto a cuáles son las dimensiones más relevantes del fenómeno. En investigaciones que adoptan un enfoque etnográfico, estas limitaciones son manejables, debido a la naturaleza del trabajo de campo -el nivel de profundidad logrado en el estudio de los fenómenos y la posibilidad de interactuar reiteradamente con los sujetos-. Sin embargo, en investigaciones que siguen otras fórmulas metodológicas (entrevistas, grupos focales, etc.), se generan complicaciones, asociadas principalmente a la delimitación de las dimensiones que debiese incluir un instrumento de recolección de datos o las categorías desde las cuales se puede realizar el análisis (Cisternas, 2017).

No obstante, las definiciones revisadas, en su conjunto, indican algunos componentes básicos para delimitar las IL. En este sentido, se observa que estas: 1) son un conjunto de ideas o creencias, 2) se refieren a las lenguas y su uso social, 3 ) tienen un carácter implícito o explícito, 4) conforman un sistema o conjunto interrelacionado, y 5) su contenido se ve influido por el contexto en el que se sitúa el sujeto. Por ende, estas deben ser entendidas como sistemas de ideas sobre una lengua, y el papel desempeñado - o que debiese desempeñar- en la sociedad, que emergen en un contexto sociopolítico y sociocultural, y que se ven influidos - aunque no determinados - por la posición ocupada por el sujeto en el espacio social (Cisternas, 2017).

Desde una perspectiva crítica, la presente revisión se limita a mostrar el conjunto de definiciones que emanan desde la escuela estadounidense, donde nace el área de estudio. No es nuestra intención generar una reflexión más profunda y compleja del término. En este sentido, la revisión es operativa, para efectos del estudio realizado. Sin embargo, con el ánimo de exponer una mirada menos descriptiva del concepto y, a su vez, complejizarlo, entendemos, junto con Del Valle (2007) y Del Valle y Merinho-Guede (2016), que la idea de IL implica la articulación de las nociones de lenguaje, lenguas, habla y comunicación con formaciones culturales y sociopolíticas específicas que circula, se produce y reproduce materialmente en las prácticas lingüísticas y metalingüísticas de los hablantes.
Según esta línea argumentativa, la IL se relaciona estrechamente con: 1) el contexto donde se produce y la manera en que este le otorga significado; 2) la forma en que naturaliza un orden social determinado, que se asocia a un conjunto de categorías y procesos sociopolíticos y culturales; y 3) intereses y espacios institucionales que posibilitan y favorecen su producción (Del Valle y MerinhoGuede, 2016). En síntesis, las IL se manifiestan a través de prácticas comunicativas orientadas a la racionalización del uso lingüístico, siendo sensibles a intereses políticos y económicos de grupos sociales hegemónicos o de la sociedad general (Kroskrity, 2010; Rojas, 2013). Los hablantes, así, conciben percepciones axiológicas y epistemológicas sobre la lengua o la variedad que se practica en su entorno local, regional, nacional o global.

\section{Método}

El método utilizado consistió en una revisión sistemática de artículos que tratan el tópico de las IL sobre las LIA, y que se hallan en la Web of Science (WoS). El corpus se conformó a partir de una búsqueda, en dicha base, de los términos "language ideology" y "language ideologies", consultando el período de 1980 a 2016. Tras este procedimiento, se obtuvo un listado de 625 trabajos, de los cuales fueron seleccionados aquellos relativos a LIA, configurando un corpus de 25 artículos publicados entre 1988 y 2016 sobre la temática.

El conjunto de 25 artículos corresponde a publicaciones realizadas en nueve revistas: Anthropological Linguistics; International Journal of American Linguistics; Journal of Language, Identity, and Education; Language and Comunication; Language in Society; Linguistic Anthropology; Pragmatics; Revista de Lingüistica Teórica y Aplicada, y Signo y Seña. Todas las revistas son del área de la lingüística o la antropología lingüística, promediando un factor de impacto de 0,87 (desviación estándar de 0,44 ). Del conjunto de artículos revisados, 22 se encuentran redactados en inglés y solo 3 en español. En total reúnen 166 citas. 
El procedimiento con el que se identificaron los aspectos relevantes de los artículos implicó tanto la revisión de los resúmenes de los trabajos como la lectura íntegra de cada uno, con el propósito de conocer: las lenguas estudiadas, el carácter (teórico o empírico) de los trabajos, los países en que desarrollaron las investigaciones, el contexto específico en que estas se llevaron a cabo, las metodologías empleadas, las ideologías identificadas y las conclusiones a las que arribaron.

\section{Resultados}

En esta sección se describe, en primer lugar, el panorama general de las publicaciones revisadas, dando cuenta de las lenguas estudiadas, los contextos y sus metodologías. Asimismo, se identifican las orientaciones teóricas predominantes, las categorías asignadas a ciertos tipos de ideologías y las líneas de investigación.

\section{Panorama general de la investigación: características, contextos y técnicas}

Entre los rasgos generales, los artículos analizados se enfocan mayoritariamente en una lengua única; solo dos realizan estudios comparados entre dos o más lenguas. En total, son 19 lenguas las abordadas en los trabajos.

Algunos de los sistemas lingüísticos estudiados son relevantes por alguna razón histórico-política, contando con números considerables de hablantes, a pesar de su situación lingüística de vulnerabilidad. En este grupo están: apache, hopi, mapudungún, náhuatl, navajo, quechua, quichua y rapa nui. Las restantes lenguas estudiadas son: kaska, keres, kumiai, maskoki, ojibwa, o'odham, pee posh, tariana, tlingit, tewa y yupik. ${ }^{1}$ Hay un trabajo (McCarty et al., 2009) que incluye una lengua no revelada, debido a compromisos éticos con los miembros de la comunidad investigada.

1 Los nombres de las lenguas se encuentran castellanizados.
El detalle de la cantidad de estudios que abarcan cada lengua se presenta en la Figura 1.

La figura evidencia que los trabajos sobre LIA se distribuyen prácticamente de forma equitativa entre lenguas habladas en América anglófona (14 artículos) y lenguas de América Latina (10 publicaciones). Una restante publicación estudia una lengua interregional: el kumiai, hablado en el sur de Estados Unidos y el norte de México.

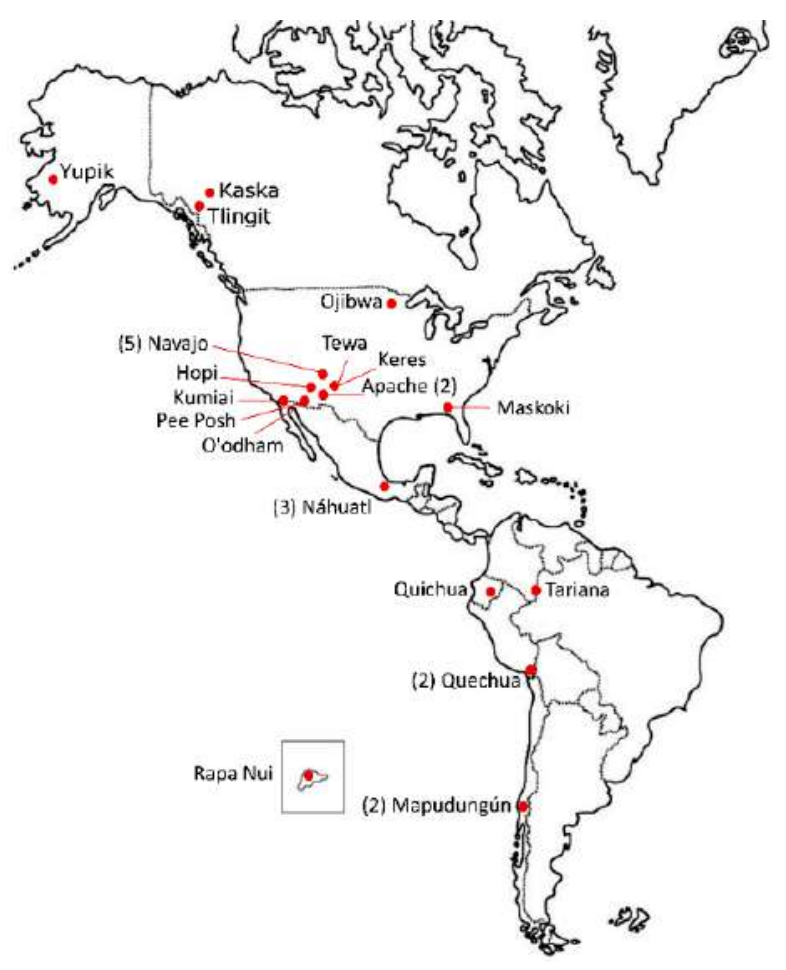

Figura 1 Lenguas indígenas americanas investigadas. Solo se indica el número en los casos en que existe más de un estudio.

En cuanto a la naturaleza de los trabajos, esta es mayoritariamente empírica, existiendo solo uno teórico (Gundermann, 2014), donde se reflexiona sobre las IL de los mapuches hacia el mapudungún, a partir de una revisión de diversos artículos sobre vitalidad y percepciones de tal lengua.

Con respecto al lugar que ocupan las IL en las investigaciones, en la Figura 2 se aprecia que, en la mayoría de los trabajos (20), estas comprenden un elemento incluido en los objetivos de la investigación. 


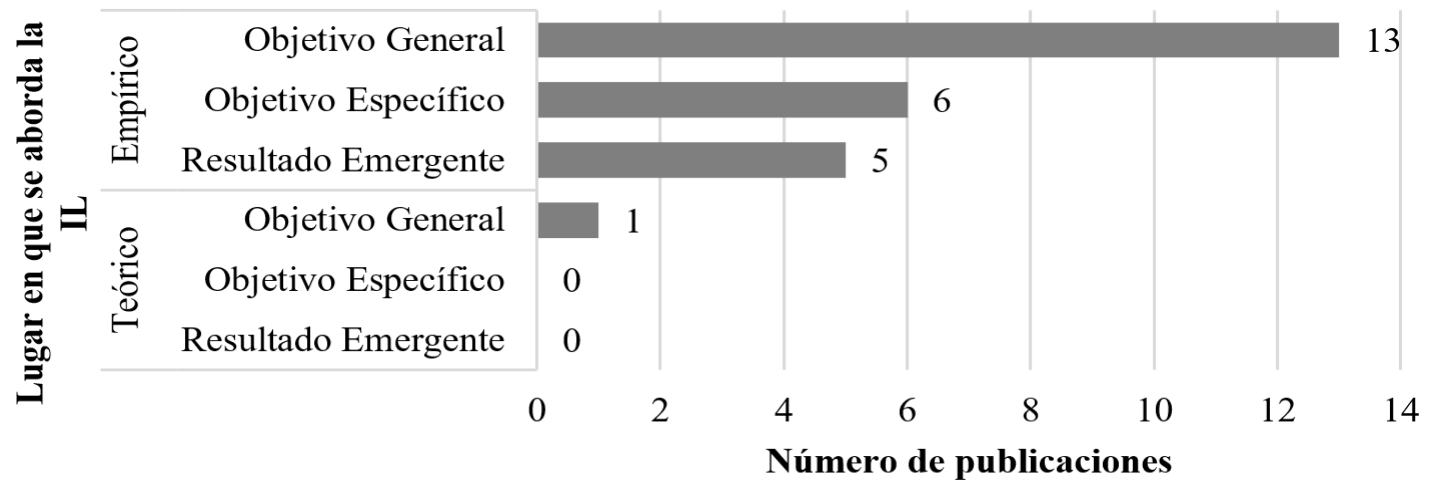

Figura 2 Lugar que ocupan las ideologías lingüísticas en las investigaciones

En 5 artículos, las IL aparecen como un resultado emergente, asociado a otro fenómeno sociolingüístico que constituye uno de los objetivos generales de los trabajos analizados, por ejemplo, la influencia de las trayectorias de vida en la reproducción de la lengua al interior de una familia, la revitalización lingüística o el uso ideofónico de la lengua en poesía étnica. Esta tendencia puede ser un indicador dela relevancia que tienen las IL en las dinámicas sociolingüísticas propias de las LIA, puesto que estas aparecen en fenómenos sociolingüísticos, aun cuando no constituyen el foco principal de la investigación.

En la Figura 3 se observa que los contextos en que se desarrollan los estudios se adscriben, mayoritariamente, a la comunidad en la que viven los hablantes. Otro conjunto de 4 investigaciones hace una revisión de documentos, donde se plantean creencias sobre las lenguas. Finalmente, hay artículos que se desarrollan vinculados a la enseñanza (escuela o instancias no formales de adquisición de la lengua), las trayectorias de vida o biografías, y talleres/seminarios sobre una determinada lengua.

El acercamiento que predomina en el plano metodológico es el cualitativo, ya que las investigaciones empíricas usan este paradigma, contrastando con la realidad mundial de los estudios, donde los instrumentos y datos cuantitativos son recursos muy difundidos —véase, por ejemplo, Stewart (2012), Sujoldžić y Šimičić (2013) y Wei (2016) - . En este aspecto, las diferencias entre los trabajos revisados se vinculan a la manera específica como se levanta la información con la que posteriormente se trabaja.

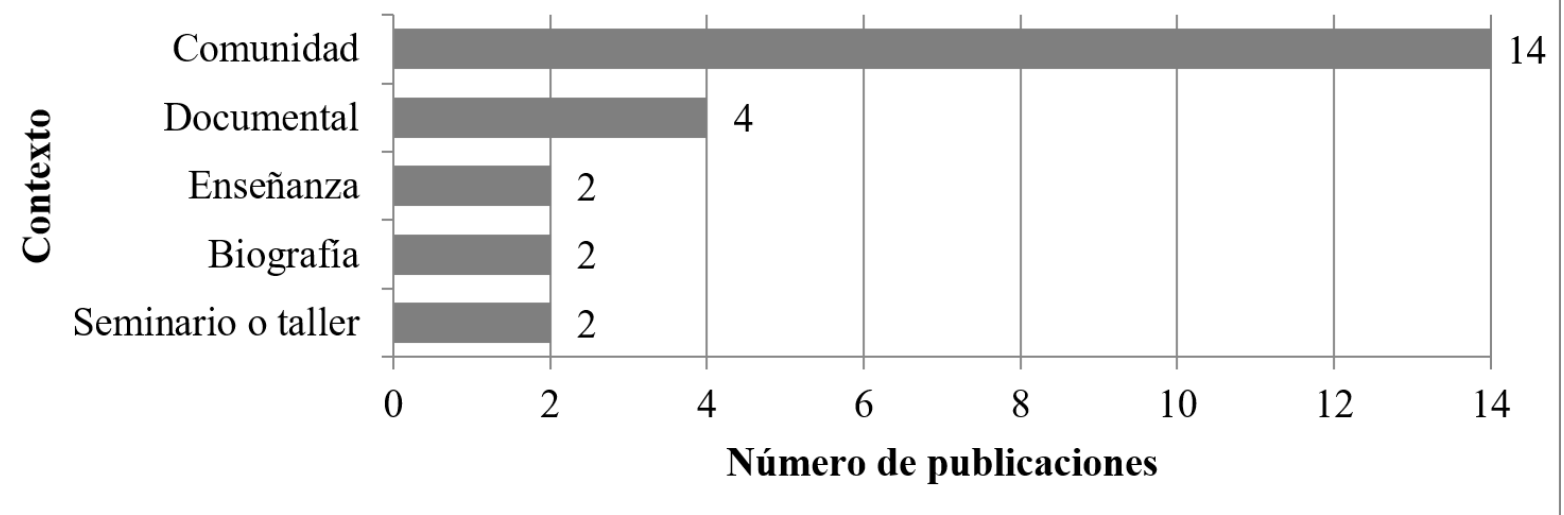

Figura 3 Contextos en los que se desarrollan las investigaciones 


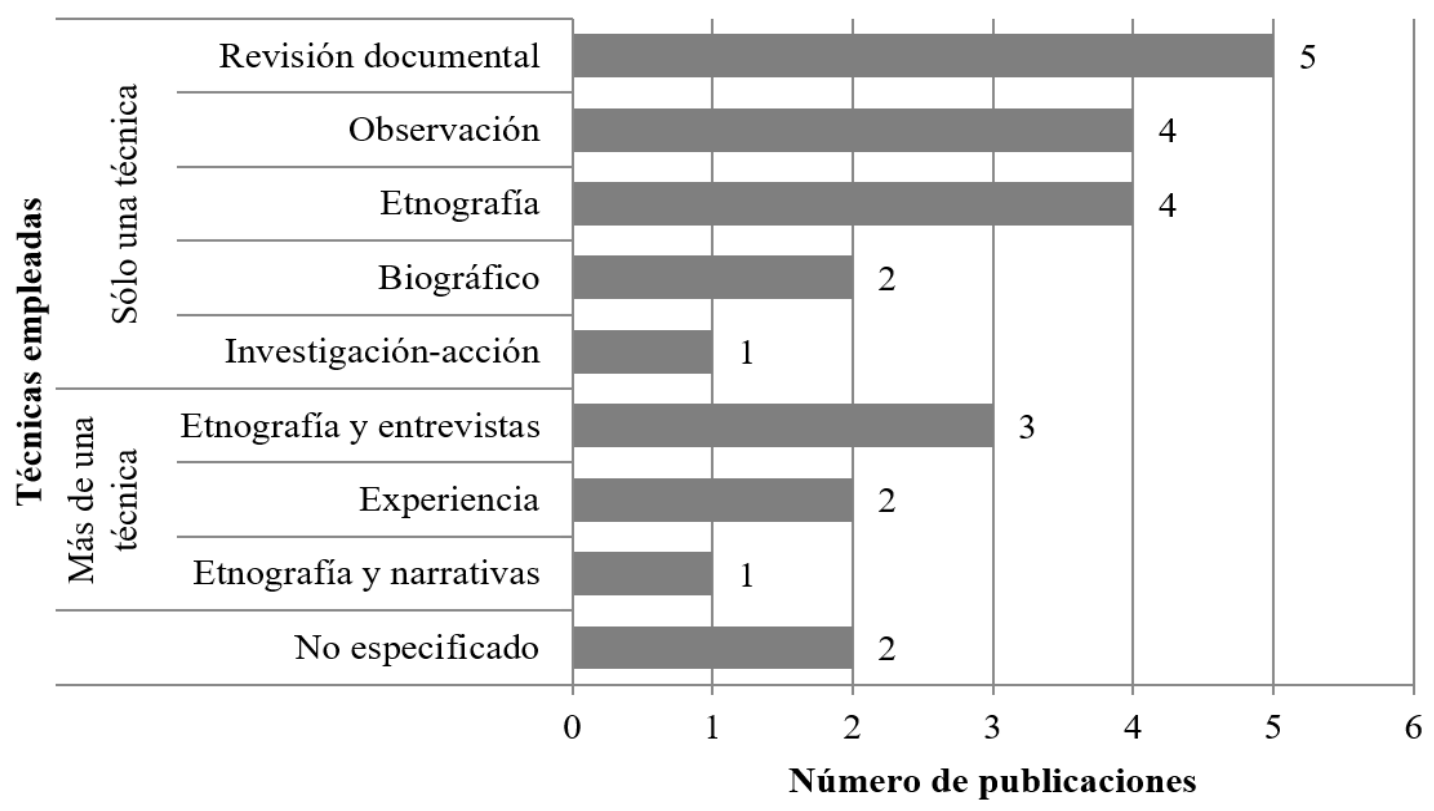

Figura 4 Acercamientos metodológicos empleados en las investigaciones

En la Figura 4 se presenta el detalle de los recursos metodológicos empleados por los artículos empíricos incluidos en el corpus.

Un tercio de las investigaciones (8) se desarrolla desde un acercamiento metodológico etnográfico, siendo la revisión documental la segunda aproximación más preferida. Otras fórmulas empleadas son la observación, el método biográfico, el análisis de datos recolectados a lo largo de varias experiencias investigativas del autor y la investigación-acción. En 2 artículos no se especifica la aproximación metodológica empleada.

De este modo, la mayor parte de las publicaciones trabaja sobre la base de datos primarios, es decir, generados por los mismos investigadores, siendo de particular relevancia a este respecto el enfoque etnográfico y la observación.

\section{Orientaciones teóricas de las investigaciones}

Los planteamientos teóricos de los artículos del corpus se sustentan en un total de 39 documentos diferentes. Tales trabajos corresponden a la producción de 16 autores, entre los cuales figuran investigadores cuyas propuestas teórico-conceptuales sobre las IL se han difundido ampliamente en este campo de estudio. La Figura 5 presenta la red de citaciones del corpus, mostrándose en azul los nodos correspondientes a los artículos incluidos en la revisión sistemática, y en gris, aquellos trabajos teóricos relativos a las IL que son citados en estos.

Como se aprecia en la red, los autores más citados son Michael Silverstein (14 citas), Paul Kroskrity (13), Kathryn Woolard (11). Los tres han sido clave en el desarrollo teórico del concepto de IL.

Sabemos que Silverstein es quien sienta las bases de esta área de estudio; sin embargo, cada uno de estos autores entrega lineamientos divergentes, hasta cierto grado, respecto de los demás, por lo que, indudablemente, el protagonismo de uno u otro autor en el marco referencial impacta en el desarrollo de la investigación. En este sentido, mientras que Silverstein, como se expuso anteriormente, destaca las IL como forma de racionalización de las estructuras lingüísticas y el uso de la lengua, Woolard se centra en la influencia que la posición social del hablante ejerce sobre las IL que este 


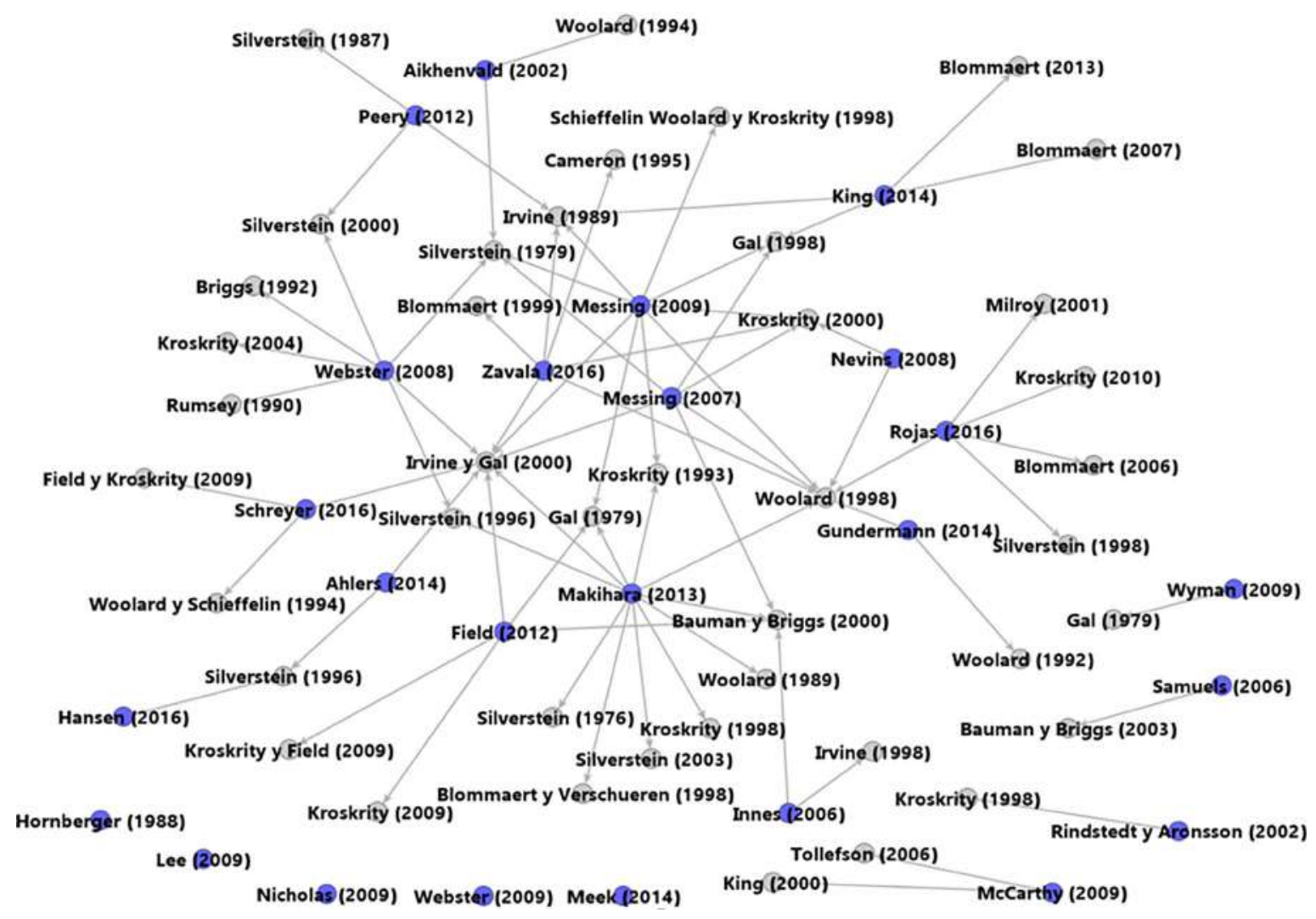

Figura 5 Redes de citaciones en las investigaciones sobre ideologías lingüísticas en lenguas indígenas americanas

adopta, y Kroskrity problematiza la dimensión afectiva que subyace a la conformación de estas creencias.

Otras autoras, cuyos trabajosson citados con frecuencia, son Susan Gal y Judith Irvine, referenciándose tanto los escritos por cada una individualmente $(7$ citas para Gal y 5 para Irvine) como aquel desarrollado en conjunto (8 citas). Entre los primeros destaca el difundido artículo de Irvine de 1989 que resalta la dimensión política y moral que subyace a las IL, mientras que el trabajo que ambas publicaron en el 2000 ha adquirido notoriedad en el campo, debido a su tesis sobre los mecanismos a partir de los cuales se construyen las distintas IL.

El resto de las referencias teóricas de los artículos analizados incluye trabajos de Richard Bauman y Charles Briggs ( 5 citas para trabajos conjuntos y 1 para un artículo de Briggs en solitario), y de Jan Blommaert
(5 citas), y de James Milroy, Alan Rumsey, Kendall King, James Tollefson y Deborah Cameron, con una cita cada uno. Además, aparecen otros dos investigadores que son citados únicamente en colaboración con otros autores: Jef Verschueren (con Blommaert) y Bambi Schieffelin (con Woolard y Kroskrity).

Cinco artículos del corpus no incluyen referencias a trabajos teóricos sobre IL; por tanto, en estos, el concepto es presentado como si fuese autoexplicativo, sin profundizar mayormente en su definición, ni en las características del proceso de formación y reproducción de esta clase de ideologías.

\section{La tipología de las ideologías lingüísticas}

En relación con los tipos de IL presentados en los artículos, se observa que trece atribuyen un rótulo particular a varias IL, resultando una tipología 
de 24 sistemas de creencias. Entre estas figuran: la ideología del respeto (Messing, 2007, 2009), del peligro lingüístico (King y Hermes, 2014), de la equivalencia con el castellano (Gundermann, 2014), monolingüista (Makihara, 2013), del derecho (entitlement) (Makihara, 2013), ambivalente (Messing, 2009), de la autenticidad (Makihara, 2013; Messing, 2009), del legítimo mexicano (Messing, 2007; 2009), de la pertenencia (Makihara, 2013), proindígena (Messing, 2009), de la diferenciación lingüística (Messing, 2007), de la lengua estándar (Rojas et al., 2016), de la lengua como un objeto unitario (Webster, 2008), monolingüe (Webster, 2008), oposicional (Webster, 2008), de la iconización (Schreyer, 2016), proquechua (Rindstedt y Aronsson, 2002), de la castellanización (Rindstedt y Aronsson, 2002), del "hablar es acción" (Innes, 2006), del variacionismo (Ahlers, 2014; Field, 2012), monoglósica de la lengua estándar (Hansen, 2016), del purismo (Messing, 2009), purista (Meek, 2014; Webster, 2008) y purismo (Aikhenvald, 2002; Gundermann, 2014; Meek, 2014; Messing, 2007, 2009; Webster, 2008).

Este abundante número de IL puede ser mejor analizado y comprendido recurriendo a una estrategia de clasificación que resulte en la conformación de conjuntos de ideologías que comparten rasgos y que pueden ser agrupados en categorías más generales. Lo anterior se puede realizar a partir del enfoque de la categorización lingüística, el cual se orienta a la organización del conocimiento en categorías jerarquizadas (Rosch, 1978). Siguiendo esta perspectiva, resulta una taxonomía que ordena las IL en función del objeto/concepto central del discurso que expresan.

Así, como se aprecia en la Tabla 1 , se tiene que en los trabajos sobre LIA se pueden encontrar ideologías relacionales, que aluden a la relación del sistema lingüístico con otras lenguas o variantes de la misma lengua; axiológicas, que dan cuenta de valores asociados a apreciaciones sobre la lengua; de proceso, cuyo foco se vincula a procesos que atraviesa una lengua; y de pertenencia, que se pronuncian respecto al vínculo entre los límites identitarios y la lengua hablada.

La tabla 1 muestra una alternativa de organización jerárquica de las IL. Se debe destacar, al hacer este ejercicio, que hay gran cantidad de denominaciones diferentes para una misma ideología, cuestión que se visibiliza al contrastar las etiquetas propuestas para las ideologías en la investigación sobre

Tabla 1 Taxonomía de ideologías lingüísticas identificadas en la investigación sobre lenguas indígenas americanas

\begin{tabular}{|c|c|c|c|}
\hline \multicolumn{4}{|c|}{ Ideologías lingiústicas } \\
\hline Relacionales & Axiológicas & De proceso & De pertenencia \\
\hline - Monolingüista & - Del derecho & - Del peligro lingüístico & - De la iconización \\
\hline - Monolingije & - Del respeto & - De la castellanización & - Del legítimo mexicano \\
\hline - Lengua como objeto unitario & - Ambivalente & & - De la pertenencia \\
\hline - Proindígena & & & - De la autenticidad \\
\hline - Proquechua & & & - Del purismo \\
\hline - Oposicional & & & - Purismo \\
\hline - Del variacionismo & & & - Purista \\
\hline \multicolumn{4}{|l|}{ - De la diferencia linguística } \\
\hline \multicolumn{4}{|l|}{ - Equivalencia con el castellano } \\
\hline \multicolumn{4}{|c|}{ - Monoglósica de la lengua estándar } \\
\hline - De la lengua estándar & & & \\
\hline
\end{tabular}

No se incluye la ideología del "hablar es acción”, puesto que no es posible incorporarla a ninguna de las categorías encontradas. Su clasificación dependerá de futuros ejercicios analíticos que incluyan otras ideologías que puedan ser agrupadas con aquella. 
LIA, con aquellas de trabajos desarrollados en otros contextos. Como se observa en la Figura 6, al comparar el corpus de LIA con el de literatura global, solo dos denominaciones se pueden encontrar en ambos corpus de artículos: ideología de la lengua estándar y la purista, lo que da cuenta de lo heterogéneo en la denominación de las IL.

La revisión de literatura internacional tuvo en cuenta los trabajos de Abouchaar (2012), Farr (2011), Ferguson (2016), FitzsimmonsDoolan (2014), Heller (1995), Hoffman (2008), König et al. (2015), Lagos et al. (2013), LippiGreen (2012), McEwan-Fujita (2010), McKinney et al. (2015), Milroy (2014), Phyak (2015), Ruuska (2016), Subtirelu (2013), Wiese (2015) y Zenker (2014).

Esta heterogeneidad muestra que cada autor define de modo propio el sistema de creencias sobre una lengua, no considerando la manera en que otros pudieron referirse anteriormente al mismo. Este hecho implica, por un lado, la proliferación de denominaciones diferentes para un mismo objeto/concepto central del discurso expresado, con lo que se complejiza la posibilidad de una sistematización de la IL en cuestión (aspecto que tratamos de salvar con la propuesta de categorización previa); y, por otro, la dificultad para generar estados del arte con más cohesión teórica, que permitan abrir la discusión sobre las distintas denominaciones y sus reales diferencias.

En la Figura 6 se aprecian cinco grupos de ideologías unidos por líneas discontinuas. Estos están conformados por IL que, a pesar de tener denominaciones diferentes, hacen mención a un mismo marco ideológico. El conjunto azul se compone por aquellas creencias que, bajo distintos nombres, aluden a la ideología de base sobre lo monolingüe (monolingüista, promonolingüismo, monolingüe, del monolingüismo institucional, monoglósica). Se observa que las denominaciones diferentes se dan incluso en aquellos casos en que se hace referencia a ciertos matices, como la ideología del monolingüismo institucional, que describe una ideología monolingüe sostenida desde las instituciones, la cual, en esencia, mantiene el foco de la definición genérica.

Por otra parte, el conjunto verde se vincula con la relación entre lengua e identidad, incluyendo las siguientes nociones: ideologíadel legitimo mexicano,

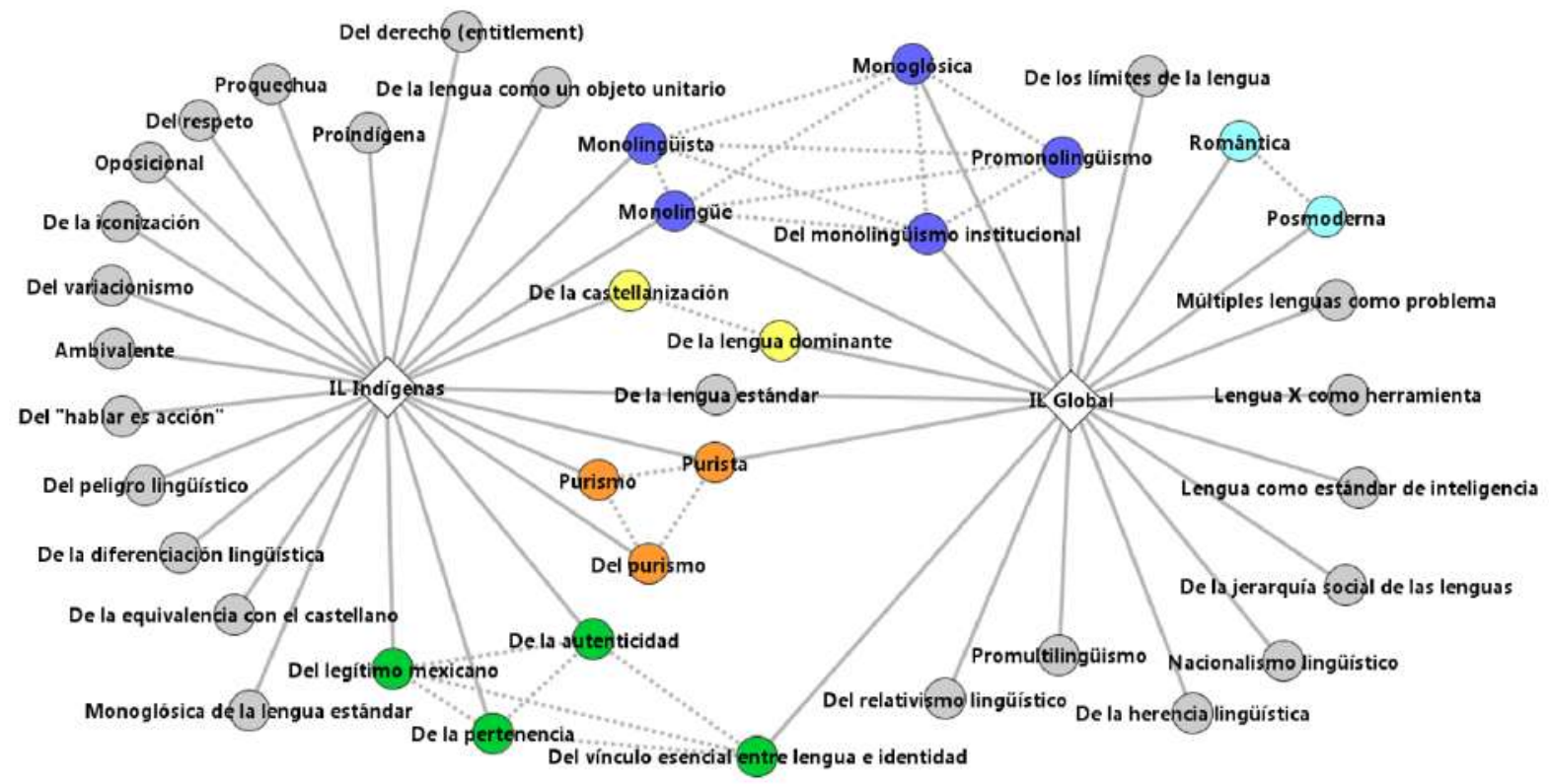

Figura 6 Ideologías en el corpus analizado y en parte de la literatura global 
de la pertenencia, del vinculo esencial entre lengua $e$ identidad y de la autenticidad. Nuevamente, es posible poner un punto en común en todas estas IL: en este caso, la idea de que un miembro auténtico de un determinado grupo debe hablar la lengua tradicionalmente asociada a tal grupo.

Lo mismo ocurre en los casos de la ideología de la castellanización-lengua dominante (amarillo), ideología del purismo-purista-purismo (naranja) y de la ideología romántica-posmoderna (celeste).

Se destacan aquí las equivalencias más explícitas; no obstante, existen otros casos, como la ideología proquechua y proindígena, en que se podría argumentar un grado de similitud considerable entre distintas etiquetas.

Varios factores podrían subyacer a esta realidad. El primero de ellos guarda relación con revisiones genéricas del estado del arte, que llevan a no incluir ciertas investigaciones y, por extensión, a pasar por alto parte de la tipología de IL existente -el hecho de que varios de los trabajos estén publicados en revistas de acceso pagado contribuiría a profundizar esta causa-. Una segunda razón podría corresponder a una cierta cuota de flexibilidad interpretativa al analizar los resultados y extraer conclusiones. Esta conduciría, por ejemplo, al uso de denominaciones diferentes para un mismo marco ideológico que se presenta en diferentes contextos. Un ejemplo se observa en la sustitución del concepto de IL monolingüe por el de IL del monolingüismo institucional, o el de IL de autenticidad por IL del legitimo $X$. En ambos casos, solo existen diferencias relacionadas al espacio en que se manifiesta la ideología: los hablantes en general/las instituciones estatales, o hablantes de cualquier procedencia/ hablantes de la lengua X. Sea como fuere, esto responde a un campo de estudio emergente, lo que explica la estructuración parcial de los marcos teóricos-conceptuales y metodológicos que guían la reflexión y la investigación empírica en este ámbito disciplinar.

Dado lo anterior, la revisión llevada a cabo en este trabajo puede contribuir a sistematizar las tipologías empleadas en el estudio de las LIA, aportando, hasta donde se pueda, a la consolidación del campo, al menos desde un dominio conceptual.

\section{Líneas de investigación y aportes al conocimiento sobre ideologías en lenguas indígenas americanas}

Las investigaciones examinadas dan cuenta de la relevancia de las IL en una serie de fenómenos sociolingüísticos y socioculturales que tienen lugar en los contextos estudiados. En la Figura 7 se aprecian con recurrencia reflexiones vinculadas con la relación lengua-identidad, la valoración de las lenguas, la revitalización lingüística, la visibilización y resistencia desde la lengua, la planificación lingüística y prácticas lingüísticas.

La identificación de múltiples líneas de investigación en las cuales aparecen las IL como un fenómeno relevante da cuenta de la importancia que adquieren en una serie de procesos sociolingüísticos asociados a las LIA. Esto refuerza la idea de que la comprensión de este tipo de sistemas de creencias sobre las LIA es trascendente para su estudio desde disciplinas como la sociolingüística y la sociología del lenguaje. A continuación, se detallan los resultados de las publicaciones según el área temática en la que se inscriben.

\section{Relación lengua-identidad}

Esta relación (7 publicaciones), en el sentido de cómo se emplea la lengua para construir la identidad indígena, evidencia que la lengua continúa siendo un elemento indexador del grupo, con lo que se articulan IL que sirven como puente entre el presente, marcado por el desplazamiento, y el futuro, entendido como una proyección del pasado en que la lengua tradicional era el medio primario de comunicación (Ahlers, 2014).

En un estudio sobre los kumiai, Field (2012) reporta el impacto que ideologías más o menos favorables a la variación lingüística tienen sobre las diferencias dialectales generadas entre comunidades. Para el autor, las divergencias ideológicas con respecto 


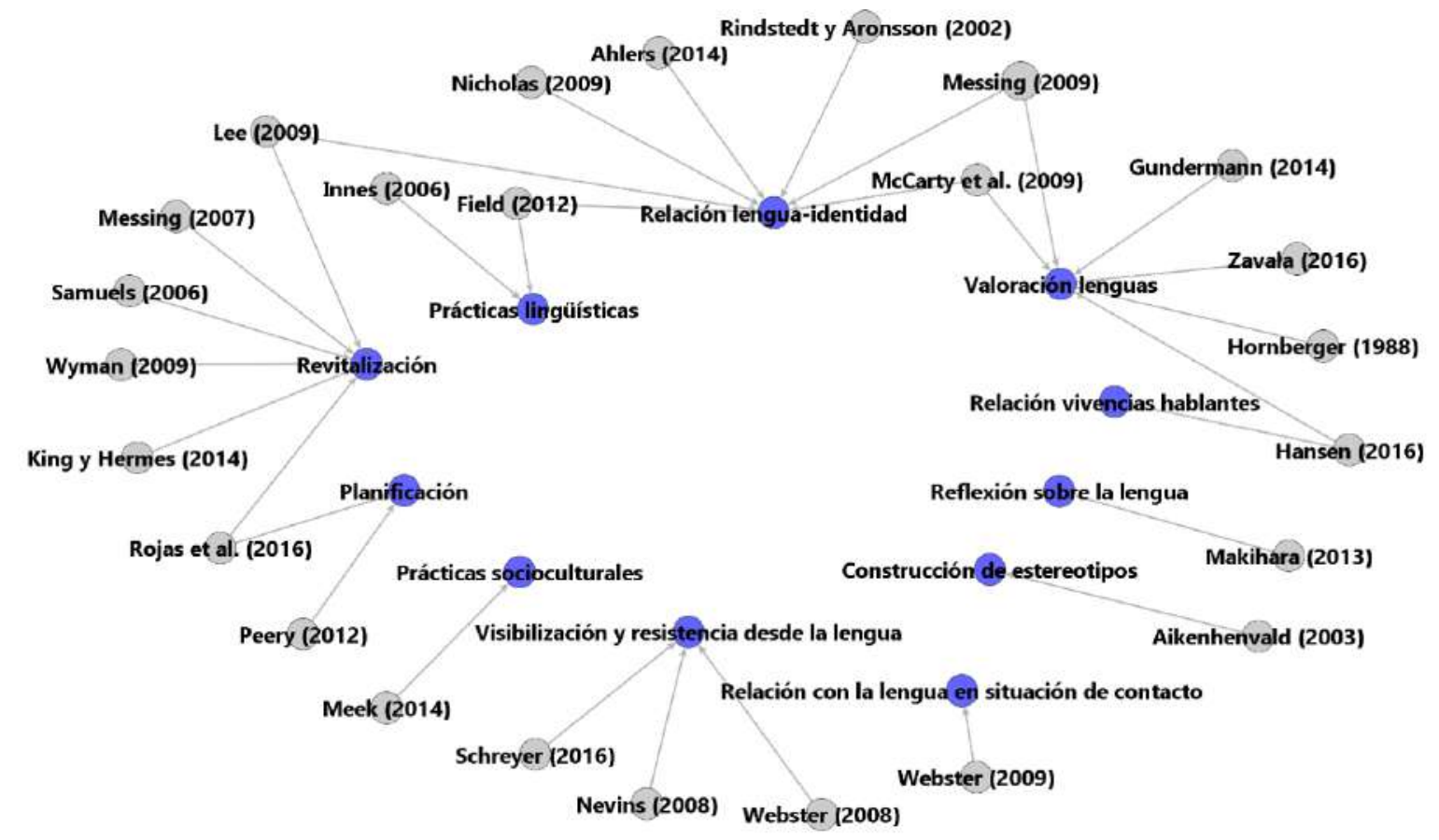

Figura 7 Temáticas abordadas en las publicaciones

a la variación están vinculadas con modos distintos de comprender la identidad propia.

Para los jóvenes navajos y pueblos, la lengua tradicional es parte primordial de la identidad; esto, a pesar de las dificultades asociadas a aprenderla y mantenerla en un contexto en que las relaciones entre la lengua dominante y la minorizada son tan asimétricas (Lee, 2009).

En un trabajo que involucra a hablantes jóvenes navajo, pima, tohono, o' odham y una de lengua no individualizada, McCarty et al. (2009) concluyen que estos mantienen IL que enfatizan la centralidad de la lengua propia en la identidad, presentándose, igualmente, sentimientos de inseguridad y vergüenza asociados a la lengua (McCarty et al., 2009).

Las diferencias generacionales en IL son también destacadas pues, en el caso del quechua, para los adultos la lengua vernácula es una parte esencial de su identidad y su herencia cultural, no así para los jóvenes, para quienes el ser quechua es algo distinto (Rindstedt y Aronsson, 2002). Cuestión similar ocurre entre los jóvenes hopi, quienes, al tener un dominio limitado de la lengua, adoptan IL que consideran la lengua como una, entre muchas formas de experimentar y aprender la propia cultura, aunque esta aparece en sus discursos como un elemento clave para una participación plena en la cultura (Nicholas, 2009).

Otro trabajo evidencia que los jóvenes náhuatl presentan ideologías ambivalentes respecto del vínculo entre la lengua y la identidad, lo que se atribuye a un contexto marcado por la discriminación racial y la globalización (Messing, 2009).

\section{Valoración de las lenguas}

La valoración de las lenguas (6 publicaciones) adquiere énfasis con las IL, al focalizar la importancia que atribuyen los propios indígenas a su lengua. De este modo, emergen reflexiones que se vinculan con la lealtad discursiva de los hablantes, a partir de la creciente revalorización que ha experimentado la lengua mapuche en las últimas décadas (Gundermann, 2014). Las trayectorias de vida de los hablantes y sus familias son factores que pueden incidir en la adquisición de una 
lengua tradicional por parte de las nuevas generaciones del náhuatl (Hansen, 2016). Para la comunidad quechua-hablante de Perú, hay una IL de lealtad al quechua, la cual ve improbable la desaparición de la lengua tradicional, al mismo tiempo que ven el español como lengua de prestigio y utilidad (Hornberger, 1988).

En otros casos, se da cuenta de que los sujetos mantienen simultáneamente IL positivas y negativas sobre una lengua determinada. En escuelas a las que asisten niños provenientes de distintos pueblos indígenas (navajo, pima, tohono, o' odham y otro no identificado), los niños expresan IL que representan, de modo positivo y negativo, tanto la propia lengua como la dominante. Mientras que la primera es asociada a la identidad, pero también a la discriminación, la segunda es vista como instrumento de colonización y, al mismo tiempo, como universal y necesaria (McCarty et al., 2009).

Entre los náhuatl se han observado ideologías que valoran de distinto modo la lengua propia, encontrándose el origen de estas divergencias en la percepción que los sujetos tienen sobre la cultura y la sociedad occidental, y sobre la tradicional (Messing, 2009).

En Perú, se ha documentado la existencia de IL negativas hacia el quechua, tanto en la élite no indígena como en un líder quechua-hablante. Estas reproducen relaciones lingüísticas jerárquicas y prácticas excluyentes hacia el quechua, difundiéndose este tipo de ideologías en la élite local (Zavala, 2016).

\section{Revitalización lingüistica}

El papel que las IL desempeñan en los procesos de revitalización de las lenguas indígenas es otro componente destacado en los trabajos revisados (6 publicaciones).

Entre las IL identificadas en este ámbito es relevante la ideología del peligro (la creencia de que la lengua está en riesgo y su desaparición es inminente), que puede mermar la disposición a aprender la lengua por parte de los no hablantes (King y Hermes, 2014).
En el caso de los jóvenes navajo, se ha evidenciado la coexistencia y la negociación de ideologías que, por un lado, conciben a la lengua dominante (inglés) como medio para el éxito en la sociedad occidental $y$, por otro, asignan un gran valor identitario a sus lenguas tradicionales (Lee, 2009).

Las IL también pueden influir en el camino que sigue un proceso de revitalización. En el caso del mapudungún, se ha documentado cómo las diferencias ideológicas entre parte de los hablantes y la élite mapuche urbana se condicen con las prioridades que cada uno de estos grupos establece en el camino a la recuperación de la lengua (Rojas et al., 2016).

Por su parte, Samuels (2006) demuestra que ciertos usos del lenguaje - la traducción de la Biblia en el caso reportado - han contribuido a modificar las IL preponderantes y volverlas más proclives a la recuperación de la lengua apache.

Otro fenómeno identificado en los contextos de LIA ha sido la ambivalencia. Entre los náhuatl, esta IL se ha expandido como consecuencia de la proliferación de discursos raciales discriminatorios en la sociedad mexicana y el contexto globalizado. Estas IL que valoran la lengua, pero no mueven a su uso, impactan en la medida en que aquellos que mantienen estas ideologías se comprometen con la revitalización de la lengua (Messing, 2007).

Finalmente, una investigación sobre los yupik revela que muchos adultos expresan IL que desaprueban el modo en que los jóvenes usan la lengua tradicional. Estos últimos, que han crecido en entornos marcados por la presencia hegemónica de la lengua dominante, han desarrollado una inseguridad lingüística, al asumir que su competencia en el yupik no es suficiente para comunicarse adecuadamente, lo que es reforzado por el rechazo de los adultos a sus prácticas lingüísticas (Wyman, 2009).

\section{Visibilización y resistencia desde la lengua}

El modo en quelas lenguas indígenas se transforman en herramientas de visibilización de la diferencia y 
la resistencia cultural también ha captado la atención de la investigación (3 publicaciones).

En esta dirección, Webster (2008) muestra cómo IL puristas y oposicionales conducen a una utilización de la lengua tradicional como mecanismo de unificación y diferenciación en la poesía navajo. En este sentido, tal poesía constituye un ideal normativo del uso correcto de la lengua, al tiempo que reproduce el imaginario de una comunidad navajo despojada de su diversidad sociolingüística y que, de ese modo, se diferencia radicalmente del no navajo angloparlante.

Las IL también han sido vinculadas a la reivindicación territorial de los tlingit. Dada la relevancia otorgada al territorio por la política indígena canadiense, ha emergido en este pueblo una IL que ve en las denominaciones empleadas en lugares, mapas, políticas de tierras y el currículo escolar una forma de visibilizar la propia identidad (Schreyer, 2016).

En una línea similar, Nevins (2008), a partir de un trabajo basado en la observación, destaca la influencia de IL en la denominación de vecindarios en una reserva apache, prácticas que son motivadas por el deseo de visibilizar la diferencia.

\section{Planificación lingüistica}

Otra de las aristas relevadas por la investigación sobre IL relacionadas a LIA es la planificación lingüística. En este ámbito se encuentran dos publicaciones: la primera da cuenta de cómo el trabajo de documentación y estandarización del navajo, a principios del siglo Xx, moldea las IL que permean la política federal estadounidense orientada a la manutención del navajo (Peery, 2012); la segunda expone las diferencias que tienen lugar entre los especialistas mapuches (con formación en disciplinas relacionadas con el lenguaje), que otorgan una importancia mayor a la planificación formal del mapudungún (estandarización y alfabetización), y los no expertos, que juzgan prioritario el fortalecimiento del prestigio de la lengua y la ampliación de los espacios en que es empleada (Rojas et al., 2016).

\section{Prácticas lingüisticas}

Una sexta línea temática guarda relación con el efecto que las creencias sobre las lenguas tienen en las prácticas lingüísticas de los sujetos (2 publicaciones).

Un estudio de los kumiai da cuenta de cómo IL más favorables a la modificación de la lengua conducen a una mayor variación léxica y morfológica que aquellas en que las IL son más puristas (Field, 2012).

Por otra parte, entre los maskoki se ha reportado que la interrelación de IL e ideologías de género resulta determinante en las prácticas lingüísticas de los sujetos, pues originan diferencias en el modo en que mujeres y hombres emplean la lengua en las ceremonias religiosas (Innes, 2006).

\section{Otras temáticas}

Otros aspectos que son evidenciados por las investigaciones en la materia ( 5 publicaciones) guardan relación con el modo en que las IL de los hablantes se configuran y modifican en función de las vivencias de los hablantes a lo largo de sus trayectorias biográficas (Hansen, 2016), el cómo las IL condicionan la reflexión de los hablantes sobre su lengua (Makihara, 2013) y el impacto que tiene el contacto del hablante con la lengua y la cultura occidental sobre la relación que este establece con su lengua tradicional y las IL que mantiene sobre aquella (Webster, 2009).

Existen otros trabajos que develan el papel que pueden desempeñar las IL en la construcción de estereotipos étnicos (Aikhenvald, 2003) y en la adopción de ciertas prácticas socioculturales (Meek, 2014).

En consecuencia, el estudio de las IL aparece como un campo importante para la comprensión cabal no solo de procesos exclusivamente sociolingüísticos, sino también de una serie de dinámicas sociales y culturales, como la adopción de ciertas formas de organización y la construcción de la identidad indígena. 


\section{Conclusiones}

El ejercicio realizado en este trabajo evidencia que las investigaciones que abordan el tema de las IL sobre las LIA representan un campo bastante marginal en los artículos de la base Web of Science, en comparación con los cientos de investigaciones en el mismo dominio sobre otraslenguas, principalmente indoeuropeas. Si bien, en los años recientes, el número de publicaciones sobre este tópico ha aumentado de manera considerable, en América del Norte, región que contribuye con la mayor parte de la investigación sobre IL en el continente, la atención se concentra en el estudio de las ideologías sobre el inglés y las lenguas de los inmigrantes.

En el plano teórico, se aprecia, en la constitución de los marcos referenciales que sustentan los trabajos, un notorio predominio de los autores más influyentes en el campo, como Michael Silverstein, Kathryn Woolard, Paul Kroskrity, Judith Irvine y Susan Gal. Mientras que, en lo metodológico, las investigaciones se plantean exclusivamente desde un paradigma cualitativo. La mayoría de estas contempla la recolección de datos primarios, siendo recurrente, en este tipo de trabajos, la aproximación metodológica etnográfica y la observacional.

Un aspecto que se debe resaltar es la variedad de nombres dados a las distintas ideologías, que resulta en la configuración de una tipología extensa y casuística. En muchos casos, varias denominaciones hacen referencia a un mismo marco ideológico, lo cual podría constituir una dificultad para la sistematización de tales ideologías. Lo anterior se atribuye a la carencia de trabajos que desarrollen revisiones exhaustivas del estado del arte de los estudios en el área, y a cierta flexibilidad interpretativa de los investigadores, aspectos que dan cuenta de un campo disciplinar emergente.

Aunque es posible que, por un lado, al estar las IL fuertemente enlazadas con sus contextos de producción y, por otro, tener una naturaleza eminentemente interdisciplinaria, la proliferación de categorías no sea un obstáculo, en cuanto evidencia su diversidad y riqueza. Sin embargo, en este punto, nuestra reflexión apunta a la posibilidad de establecer una sistematización del conjunto de trabajos y nombres que los diversos investigadores han dado a las ideologías, buscando elementos comunes que permitan generar una red de relaciones de IL. Dicho de otra manera, la observación planteada sugiere una categorización cuyo propósito no sería otro que sistematizar la diversidad a partir de puntos comunes. En esta dirección, se propone, como una forma de contribuir a la facilitación de esta tarea, una categorización para clasificar las IL, compuesta por cuatro dominios: relacionales, axiológicas, de proceso y de pertenencia.

Por otra parte, el ejercicio realizado constata la aparición de las IL en ámbitos como la relación lengua-identidad, la valoración de las lenguas, la revitalización lingüística, la visibilización y resistencia desde la lengua, la valoración de las lenguas y la planificación lingüística, entre otras temáticas. Esto evidencia su relevancia en distintos procesos sociales y lingüísticos asociados a las LIA. Incluso, en algunos casos, condicionan el modo en que se llevan a cabo determinadas prácticas socioculturales.

Una posible proyección de este trabajo se relaciona con estudiar los modos de circulación y los recursos lingüísticos utilizados por los hablantes para movilizar las IL de lenguas minorizadas. Esta revisión puede ser un aporte para observar la relación entre las representaciones, el contexto, la institucionalidad y los procesos sociopolíticos y culturales en que emergen.

Los resultados expuestos en esta investigación contribuyen a la sistematización del área de estudio, representando un insumo importante para su consolidación, en cuanto dan cuenta de las principales tendencias teóricas, metodológicas y empíricas del campo. No obstante, nuevas revisiones sistemáticas resultan necesarias para retratar el panorama general de la investigación respecto de las IL de las 
LIA. En este sentido, revisiones sobre bases como Scielo, Redalyc y DOAJ arrojarán más luces sobre el estado general de la investigación en cuanto a las IL acerca de estas lenguas, particularmente en América Latina, pues la mayoría de las revistas latinoamericanas indexadas se encuentran en estas bases. Tal ejercicio constituiría un gran aporte para complementar la mirada sobre las publicaciones de mayor impacto que se ha realizado en el presente trabajo.

\section{Referencias}

Abouchaar, A. (2012). Contra el hablante/oyente ideal y la ideología del monolingüismo. Forma y Función, 25(2), 85-97. http://www.scielo.org.co/scielo. php?script $=$ sci_arttext\&pid=S0120-338X2012000 200004\&lng=en\&nrm $=$ iso\&tlng=es

Ahlers, J. (2014). Linguistic variation and time travel: Barrier, or border-crossing? Language \& Communication, 38, 33-43. https://doi.org/10.1016/j. langcom.2014.07.002

Aikhenvald, A. (2002). Multilingualism and ethnic stereotypes: The Tariana of northwest Amazonia.Language in Society, 32(1), 1-21. https://doi.org/10.1017/ S0047404503321013

Brown, K. (2006). Encyclopedia of language and linguistics (2. ${ }^{\mathrm{a}}$ ed.). Elsevier.

Cisternas, C. (2017). Ideologías lingüísticas: hacia una aproximación interdisciplinaria a un concepto complejo. Lenguas y Literaturas Indoamericanas, 19(1), 101-117. http://revistas.ufro.cl/ojs/index.php/ indoamericana/article/view/930

Del Valle, J. (2007). La lengua, ¿patria común? Ideas e ideologías del español. Iberoamericana.

Del Valle, J., y Meirinho-Guede, V. (2016). Ideologías lingüísticas. En J. Gutiérrez-Rexach (Ed.), Enciclopedia de lingüística hispánica (pp. 622-631). Routledge.

Farr, M. (2011). Urban plurilingualism: Language practices, policies, and ideologies in Chicago. Journal of Pragmatics, 43(5), 1161-1172. https://doi. org/10.1016/j.pragma.2010.10.008

Ferguson, J. (2016). Code-mixing among Sakha-Russian bilinguals in Yakutsk: A spectrum of features and shifting indexical fields. Journal of Linguistic Anthropology, 26(2), 141-161. https://doi.org/10.1111/jola.12123

Field, M. (2012). Kumeyaay language variation, group identity, and the land. International Journal of
American Linguistics, 78(4), 557-573. https://doi. org/10.1086/667451

Fitzsimmons-Doolan, S. (2014). Language ideologies of Arizona voters, language managers, and teachers. Journal of Language, Identity \& Education, 13(1), 34-52. https://doi.org/10.1080/15348458.2014.864211

Garrett, P. (2010). Attitudes to language. Cambridge University Press. https://doi.org/10.1017/CBO9780511844713

Gundermann, H. (2014). Orgullo cultural y ambivalencia: actitudes ante la lengua originaria en la sociedad mapuche contemporánea. Revista de Lingüistica Teórica y Aplicada, 52(1), 105-132. https:// doi.org/10.4067/S0718-48832014000100006

Hansen, M. (2016). The difference language makes: The life-history of Nahuatl in two Mexican families. Journal of Linguistic Anthropology, 26(1), 81-97. https://doi.org/10.1111/jola.12115

Heller, M. (1995). Language choice, social institutions, and symbolic domination. Language in Society, 24(3), 373-405. https://doi.org/10.1017/ S0047404500018807

Hoffman, K. (2008). Purity and contamination: Language ideologies in French colonial native policy in Morocco. Comparative Studies in Society \& History, 50(3), 724-752. https://doi.org/10.1017/ S0010417508000315

Hornberger, N. (1988). Language ideology in Quechua communities of Puno, Peru. Anthropological Linguistics, 30(2), 214-235. https://www.jstor.org/ stable/30027980

Innes, P. (2006). The interplay of genres, gender, and language ideology among the Muskogee. Language in Society, 35(2), 231-259. https://doi.org/10.1017/ S0047404506060106

Irvine, J. (1989). When talk isn't cheap: Language and political economy. American Ethnologist, 16(2), 248-267. https://doi.org/10.1525/ae.1989.16.2.02a00040

King, K., y Hermes, M. (2014). Why is this so hard?: Ideologies of endangerment, passive language learning approaches, and Ojibwe in the United States. Journal of Language, Identity \& Education, 13(4), 268-282. https://doi.org/10.1080/15348458.2014.939029

König, K., Dailey-O'Cain, J., y Liebscher, G. (2015). A comparison of heritage language ideologies in interaction. Journal of Sociolinguistics, 19(4), 484-510. https://doi.org/10.1111/josl.12146

Kroskrity, P. (2004). Language ideologies. En A. Duranti (Ed.), A companion to linguistic anthropology 
(pp. 496-517). Blackwell Publishing. https://doi. org/10.1002/9780470996522.ch22

Kroskrity, P. (2010). Language ideologies - Evolving perspectives. En J. Jaspers, J. Östman y J. Verschueren (Eds.), Society and language use (pp. 192-211). John Benjamins. https://doi.org/10.1075/hoph.7.13kro

Lagos, C., Espinoza, M., y Rojas, D. (2013). Mapudungun according to its speakers: Mapuche intellectuals and the influence of standard language ideology. Current Issues in Language Planning, 14(3-4), 403-418. https://doi.org/10.1080/14664208.2013.828879

Lee, T. (2009). Language, identity, and power: Navajo and Pueblo young adults' perspectives and experiences with competing language ideologies. Journal of Language, Identity \& Education, 8(5), 307-320. https:// doi.org/10.1080/15348450903305106

Lippi-Green, R. (2012). English with an accent. Language, ideology and discrimination in the United States (2. ${ }^{2}$ ed.). Routledge. https://doi.org/10.4324/9780203348802

Makihara, M. (2013). Language, competence, use, ideology, and community on Rapa Nui. Language and Communication, 33(4), 439-449. https://doi. org/10.1016/j.langcom.2013.03.005

McCarty, T., Romero-Little, E., Warhol, L., y Zepeda, O. (2009). Indigenous youth as language policy makers. Journal of Language, Identity \& Education, 8(5), 291-306. https://doi. org/10.1080/15348450903305098

McEwan-Fujita, E. (2010). Ideology, affect, and socialization in language shift and revitalization: The experiences of adults learning Gaelic in the Western Isles of Scotland. Language in Society, 39(1), 27-64. https://doi.org/10.1017/S0047404509990649

McKinney, C., Carrim, H., Marshall, A., y Layton, L. (2015). What counts as language in South African schooling?: monoglossic ideologies and children's participation. AILA Review, 28, 103-126. https:// doi.org/10.1075/aila.28.05mck

Meek, B. (2014). "She can do it in English too": Acts of intimacy and boundary-making in language revitalization. Language \& Communication, 38, 73-82. https://doi.org/10.1016/j.langcom.2014.05.004

Messing, J. (2007). Multiple ideologies and competing discourses: Language shift in Tlaxcala, Mexico. Language in Society, 36(4), 555-577. https://doi. org/10.1017/S0047404507070443

Messing, J. (2009). Ambivalence and ideology among Mexicano youth in Tlaxcala, Mexico. Journal of Language,
Identity \& Education, 8(5), 350-364. https://doi. org/10.1080/15348450903307680

Milroy, J. (2014). Sociolinguistics and ideologies in language history. En J. Hernández-Campoy y J. Conde-Silvestre (Eds.), The handbook of historical sociolinguistics (pp. 571-584). Wiley Blackwell.

Nevins,M.(2008). “Theylive in LonesomeDove”:Media and contemporary Western Apache place-naming practices. Language in Society, 37(2), 191-215. https:// doi.org/10.1017/S0047404508080263

Nicholas, S. (2009). "I live Hopi, I just don't speak it" - The critical intersection of language, culture, and identity in the lives of contemporary Hopi youth. Journal of Language, Identity \& Education, 8(5), 321-334. https://doi.org/10.1080/15348450903305114

Olate, A., Cisternas, C., Wittig, F., y Flores, J. (2017). Los misioneros capuchinos bávaros y sus ideologías lingüisticas sobre la lengua mapuche. Nueva Revista del Pacifico, (67), 130-156. https://scielo.conicyt.cl/ $\mathrm{pdf} / \mathrm{nrp} / \mathrm{n} 67 / 0719-5176-\mathrm{nrp}-67-00130 . \mathrm{pdf}$

Peery, C. (2012). New Deal Navajo linguistics: language ideology and political transformation. Language \& Communication, 32(2), 114-123. https://doi. org/10.1016/j.langcom.2011.05.003

Phyak, P. (2015). (En)countering language ideologies: Language policing in the ideospace of Facebook. Language Policy, 14(4), 377-395. https://doi. org/10.1007/s10993-014-9350-y

Rindstedt, C., y Aronsson, K. (2002). Growing up monolingual in a bilingual community: The Quichua revitalization paradox. Language in Society, 31(5), 721-742. https://doi.org/10.1017/ S0047404502315033

Rojas, D. (2013). Actitudes e ideologías de hispanohablantes en torno a las lenguas indígenas en el Chile del siglo XIX. Lenguas Modernas, (42), 85-98. https:// lenguasmodernas.uchile.cl/index.php/LM/article/ view/32240

Rojas, D., Lagos, C., y Espinoza, M. (2016). Ideologías lingüísticas acerca del mapudungun en la urbe chilena: el saber tradicional y su aplicación a la revitalización lingüística. Chungará, 48(1), 115-125. https://doi. org/10.4067/S0717-73562015005000034

Rosch, E. (1978). Principles of categorization. En E. Rosch y B. Lloyd (Eds.), Cognition and categorization (pp. 27-48). Laurence Erlbaum Associates.

Ruuska, K. (2016). Between ideologies and realities: Multilingual competence in a languagised world. Applied 
Linguistics Review, 7(3), 353-374. https://doi. org/10.1515/applirev-2016-0015

Samuels, D. (2006). Bible translation and medicine man talk: Missionaries, indexicality, and the "language expert" on the San Carlos Apache Reservation. Language in Society, 35(4), 529-557. https://doi.org/10.1017/ S0047404506060246

Schreyer, C. (2016). Taku River Tlingit genres of place as performative of stewardship. Journal of Linguistic Anthropology, 26(1), 4-25. https://doi. org/10.1111/jola.12109

Silverstein, M. (1979). Language structure and linguistic ideology. En P. Clyne, W. Hanks y C. Hofbauer (Eds.), The elements: a parasession on linguistic units and beliefs (pp. 193-247). Chicago Linguistic Society.

Spolsky, B. (2004). Language policy. Cambridge University Press.

Stewart, C. M. (2012). Mapping language ideologies in multi-ethnic urban Europe: The case of Parisian French. Journal of Multilingual and Multicultural Development, 33(2), 187-202. https://doi.org/10.1 $080 / 01434632.2011 .617821$

Subtirelu, N. (2013). "English... it's part of our blood": Ideologies of language and nation in United States Congressional discourse. Journal of Sociolinguistics, 17(1), 37-65. https://doi.org/10.1111/josl.12016

Sujoldžić, A., y Šimičić, L. (2013). Public and private language ideologies as reflected in language attitudes on the Island of Korčula. Collegium Antropologicum, 37(2), 323-334. https://www.collantropol.hr/ antropo/article/view/191

Unicef (2009). Atlas sociolingüistico de pueblos indigenas en América Latina 1. Unicef y Funproib Andes. https://www.unicef.org/lac/media/9791/file/ PDF\%20Atlas\%20sociolinguistico $\% 20 \mathrm{de} \% 20$ pueblos\%20ind\%C3\%ADgenas\%20en\%20ALCTomo\%201.pdf
Webster, A. (2008). "Plaza 'góó and before he can respond...": language ideology, bilingual Navajo, and Navajo poetry. Pragmatics, 18(3), 511-541. https:// doi.org/10.1075/prag.18.3.08web

Webster, A. (2009). The poetics and politics of Navajo ideophony in contemporary Navajo poetry. Language \& Communication, 29,(2), 133-151. https://doi. org/10.1016/j.langcom.2008.12.005

Wei, M. (2016). Language ideology and identity seeking: Perceptions of college learners of English in China. Journal of Language, Identity \& Education, 15(2), 100-113. https://doi.org/10.1080/15348458.2015 .1137477

Wiese, H. (2015). “This migrants' babble is not a German dialect!": The interaction of standard language ideology and "us"/"them" dichotomies in the public discourse on a multiethnolect. Language in Society, 44(4), 341-368. https://doi.org/10.1017/ S0047404515000226

Woolard, K. (1998). Introduction: Language ideology as a field of inquiry. En B. Schieffelin, K. Woolard y P. Kroskrity (Eds.), Language ideology. Practice and theory (pp. 3-47). Oxford University Press.

Wyman, L. (2009). Youth, linguistic ecology, and language endangerment: A Yup'ik example. Journal of Language, Identity \& Education, 8(5), 335-349. https:// doi.org/10.1080/15348450903305122

Zavala, V. (2016). Ideologías sobre el quechua desde el poder: una aproximación discursiva. Signo y Seña, (29), 207-234. http://revistascientificas.filo.uba.ar/ index.php/sys/article/view/2812/2442

Zenker, O. (2014). Linguistic relativity and dialectical idiomatization: Language ideologies and second language acquisition in the Irish language revival of Northern Ireland. Journal of Linguistic Anthropology, 24(1), 63-83. https://doi.org/10.1111/ jola. 12037

Cómo citar este artículo: Cisternas Irarrázabal, C., y Olate Vinet, A. (2020). Las ideologías lingüísticas sobre las lenguas indígenas americanas: una revisión sistemática de artículos de investigación. Íkala, Revista de Lenguaje y Cultura, 25(3), 755-773. https://doi.org/10.17533/udea.ikala.v25n03a09 